\title{
BMJ Open Influence of pre-existing inflammation on the outcome of acute coronary syndrome: a cross-sectional study
}

\author{
Jacob Odeberg, ${ }^{1,2}$ Michael Freitag, ${ }^{3}$ Henrik Forssell, ${ }^{4}$ Ivar Vaara, ${ }^{5}$ \\ Marie-Louise Persson, ${ }^{5}$ Håkan Odeberg, ${ }^{4}$ Anders Halling, ${ }^{6}$ Lennart Råstam, ${ }^{7}$ \\ Ulf Lindblad ${ }^{8}$
}

To cite: Odeberg J, Freitag $\mathrm{M}$, Forssell $\mathrm{H}$, et al. Influence of pre-existing inflammation on the outcome of acute coronary syndrome: a cross-sectional study. BMJ Open 2016;5:e009968. doi:10.1136/bmjopen-2015009968

- Prepublication history for this paper is available online. To view these files please visit the journal online (http://dx.doi.org/10.1136/ bmjopen-2015-009968).

Received 11 September 2015 Revised 24 November 2015 Accepted 25 November 2015

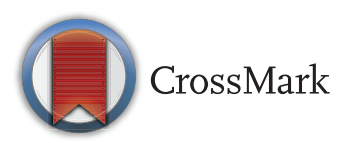

For numbered affiliations see end of article.

Correspondence to Dr Jacob Odeberg; jacob. odeberg@scilifelab.se

\section{ABSTRACT}

Objectives: Inflammation is a well-established risk factor for the development of coronary artery disease (CAD) and acute coronary syndrome (ACS). However, less is known about its influence on the outcome of ACS. The aim of this study was to determine if blood biomarkers of inflammation were associated specifically with acute myocardial infarction (MI) or unstable angina (UA) in patients with ACS.

Design: Cross-sectional study.

Setting: Patients admitted to the coronary care unit, via the emergency room, at a central county hospital over a 4-year period (1992-1996).

Participants: In a substudy of Carlscrona Heart Attack Prognosis Study (CHAPS) of 5292 patients admitted to the coronary care unit, we identified 908 patients aged 30-74 years, who at discharge had received the diagnosis of either MI (527) or UA (381).

Main outcome measures: $\mathrm{MI}$ or $\mathrm{UA}$, based on the diagnosis set at discharge from hospital.

Results: When adjusted for smoking, age, sex and duration of chest pain, concentrations of plasma biomarkers of inflammation (high-sensitivity $C$ reactive protein $>2 \mathrm{mg} / \mathrm{L}(\mathrm{OR}=1.40$ (1.00 to 1.96$)$ and fibrinogen ( $p$ for trend $=0.035)$ ) analysed at admission were found to be associated with MI over UA, in an event of ACS. A strong significant association with MI over UA was found for blood cell markers of inflammation, that is, counts of neutrophils ( $p$ for trend $<0.001$ ), monocytes ( $p$ for trend $<0.001$ ) and thrombocytes ( $p$ for trend $=0.021$ ), while lymphocyte count showed no association. Interestingly, eosinophil count ( $p$ for trend $=0.003$ ) was found to be significantly lower in patients with MI compared to those with UA.

Conclusions: Our results show that, in patients with ACS, the blood cell profile and degree of inflammation at admission was associated with the outcome. Furthermore, our data suggest that a pre-existing low-grade inflammation may dispose towards MI over UA.

\section{INTRODUCTION}

Acute coronary syndrome (ACS) is usually initiated by an atherosclerotic plaque rupture or disruption of the overlying endothelial

\section{Strengths and limitations of this study}

- The patients were recruited before the introduction of percutaneous coronary intervention, coronary artery bypass graft and modern antithrombotic drugs in the standard management of acute coronary syndrome (ACS). Thus, it was possible to identify progression to unstable angina (UA) or myocardial infarction (MI) as distinct outcome groups within the cohort, in the absence of interventions that would otherwise influence the thrombotic processes involved in ACS.

- The study was based in a single centre with the same two cardiologists evaluating and categorising all 5292 patients, using consistent criteria.

- Some of the UA cases would likely have been diagnosed as non-ST elevation MI, using the most recent criteria of MI.

- Treatments and risk factor profiles have partly evolved since the study was performed.

surface. Subsequent thrombosis formation can permanently occlude the lumen of a coronary artery, causing myocardial cell death and the induction of myocardial infarction (MI). However, in other cases, it can be transient, or only partially occlude the vessel, resulting in unstable angina (UA) ${ }^{12}$ It is not known why some patients progress to the former, rather than the latter, outcome. It is well established that low-grade inflammation has a major pathogenic role for the progression of atherosclerotic coronary artery lesions. ${ }^{12}$ A role for inflammatory mediators during the evolution of ACS is indicated by the widespread coronary inflammation found during UA, throughout the entire coronary artery bed, and not only in the artery containing the culprit lesion. ${ }^{3}{ }^{4}$ To what extent ACS outcome is related to a concurrent inflammatory response or to the degree of pre-existing inflammation is less established. $^{25}$ 
The Carlscrona Heart Attack Prognosis Study (CHAPS) constitutes a patient cohort recruited before the introduction of percutaneous coronary intervention (PCI), coronary artery bypass graft (CABG) surgery and modern antithrombotic drugs, in the management of patients with ACS. Thus, to the best of our knowledge, this study is unique in that MI and UA could be identified as distinct groups within an ACS population. In a previous CHAPS report, we demonstrated that smoking, or impaired glucose homoeostasis, were acquired risk factors for a severe ACS outcome. ${ }^{6}$ In the current study, the aim was to determine if blood biomarkers of inflammation, for example, high-sensitivity $\mathrm{C}$ reactive protein (hsCRP), serum amyloid protein A (SAA), plasma fibrinogen, and blood cell counts and indices, are associated specifically with either acute MI or UA in patients with ACS.

\section{MATERIALS AND METHODS}

\section{Study design}

We performed a substudy of CHAPS of patients with suspected ACS. In this observational cohort substudy, we included patients diagnosed with either MI or with UA.

\section{Patient recruitment}

The patient data have been previously described in detail. ${ }^{6}$ In brief, in CHAPS, we recruited 5292 consecutive patients admitted to the coronary intensive care unit with acute chest pain (indicative of a possible ACS) at Blekinge Hospital, Karlskrona, between 26 January 1992 and 25 January 1996. Of the total number of admittances, 2992 were between 30 and 74 years of age at admittance. In patients with multiple admittances, only the first classifying admittance was included as 'event' (UA or MI) in the analysis. Informed consent was obtained from all included patients and the study complies with the Declaration of Helsinki.

\section{Outcome measures}

UA or MI as diagnosed at discharge from hospital.

\section{Patients with ACS}

As previously described, a diagnosis of ACS was confirmed in 908 of the eligible patients 30-74 years of age (644 men and 264 women). ${ }^{6}$ Two groups were identified: (1) patients experiencing at least one acute MI during the study (527) or (2) patients experiencing no acute MI, but having at least one episode of UA during the study (381). Data on environmental and lifestyle factors, and blood samples, were collected on first admittance under the classifying diagnosis. The classifying diagnosis was set at discharge by one of two experienced cardiologists.

A diagnosis of acute MI was made when patients fulfilled at least two of the following criteria: (1) a history of chest pain of at least 15 min duration, (2) an increase in activity of cardiac enzymes to at least twice the upper limit of normality, or (3) characteristic ECG changes for
MI (typical sequence change of ST segment and/or of T-waves and/or appearance of new Q-waves). These criteria included both patients with ST-elevation MI (STEMI) and those with non-STEMI (NSTEMI).

A diagnosis of UA was made when patients fulfilled all of the following criteria: (1) no evidence of MI, (2) acute chest pain of increased/modified character to any previously experienced, during the preceding $48 \mathrm{~h}$ and (3) angina pectoris diagnosed and medically treated before admission, or alternatively, angina pectoris ascertained by clinical evaluation, including a bicycle exercise test, prior to discharge from the hospital. ${ }^{6}$ Post-infarction angina and patients with secondary angina were not included.

Patients admitted to the coronary intensive care unit were initially treated with aspirin and also-in case of ongoing chest pain-nitrates and morphine. In cases of clear diagnosis of ST elevation MI, thrombolysis with streptokinase was given (194 of 527 patients with MI). If the diagnosis of MI was based on cardiac markers only, thrombolysis was not given. Acute coronary artery intervention was not available at this hospital at the time of the study.

\section{Risk factors}

Information on risk factors and medical history were recorded at admission from patient history and/or extracted from earlier medical files, and the diagnosis and information were also verified at discharge from the hospital. ${ }^{6}$ Smoking status was defined as current smoker or non-smoker. Patients who had quit smoking $>1$ month prior to admission were classified as non-smokers.

\section{Laboratory analyses}

Samples for laboratory analysis were collected at hospital admission. A standardised protocol for obtaining data for selected laboratory parameters was used. The procedures for blood sampling and laboratory analyses followed the routine of the Department of Clinical Chemistry at Blekinge County Hospital and analyses were performed in the certified hospital laboratory. Haematological variables (blood cell count and indices) and plasma fibrinogen were analysed using routine diagnostic methods in fresh samples at the time of admission. Blood cell count was analysed in EDTA whole blood by ADVIA 2120 (Siemens, Germany) and plasma fibrinogen in sodium citrate blood samples on a Trombotrack instrument (Nycomed, Norway). Results were extracted from the computerised hospital laboratory records and entered into the study database. hsCRP and SAA were analysed in samples that had been stored at $-80^{\circ} \mathrm{C}$, after thawing. Both proteins were analysed by BN ProSpec (Siemens, Germany). These results were entered directly into the study database. The service provided by the laboratory is subject to regular internal precision and accuracy checks, as well as external quality 
control measures, in accordance with the guidelines of the Association of Clinical Chemists in Sweden. The external control system used is EQUALIS, Sweden, and Bio Rad UKNEQAS, England. The instruments from Roche and Siemens are validated according to the IVD directive. The verification performed by the laboratory includes intra-assay precision, correctness of measure intervals, minimal detectable concentration, interferences, pre-analytical factors, and blood collection and handling. All laboratory results reported from the laboratory and included in the study are within determined intra-assay range for each assay method.

\section{Statistical methods}

STATA and IBM SPSS Statistics (V.21) were used for data analyses. Standard methods were used for descriptive statistics. Associations were estimated by binary logistic regression and presented by ORs with $95 \%$ CIs and $\mathrm{p}$ values. Tests for trends were performed using the continuous format of the variables, and the results are presented as $\mathrm{p}$ values. However, for concentrations of fibrinogen, eosinophil cell count and thrombocyte median cell volumes, the tertiles were entered as linear variables to test for trend due to skewed distributions of these variables. Two-way interaction terms were used to explore the association of sex and the major risk factors with ACS outcome.

Age was entered into the regressions as continuous variable. Duration of chest pain from onset to blood sampling on admission to the emergency room (ER) was divided in $\geq 4 \mathrm{~h}$ or $<4 \mathrm{~h}$. Plasma levels of hsCRP were dichotomised at $2 \mathrm{mg} / \mathrm{L}$ to categorise individuals into high-risk and low-risk groups. This cut-off is based on the JUPITER study, which selected individuals at high vascular risk because of an enhanced inflammatory response as indicated by hsCRP levels $\geq 2 \mathrm{mg} / \mathrm{L} .{ }^{7}$ For other biomarkers, to categorise into risk groups we divided these into tertiles, using tertile 1 as reference to obtain measures of relative risks. The tertiles were then entered into the regression as a linear variable to test for trend. Confounding was considered by stratification and by multivariate regression models forcing age, sex, current smoking and duration $\geq 240$ min into the same model. Individuals with a missing variable were automatically excluded in the respective analysis, thus each multivariate analysis includes only those with full data for every variable included. As an example, for analyses of neutrophils, 86 patients were excluded when adjusted for age and sex only, but 268 were excluded when also adjusting for smoking and duration of chest pain. Numbers remaining in the regression were accordingly $822(90 \%)$ and $640(70 \%)$, respectively.

\section{RESULTS}

We included 908 patients with ACS (527 MI, 381 UA). Patient characteristics are shown in tables 1 and 2 . Outcome was similar in men and women, with no significant interaction between sex and markers of inflammation associated with the outcome of ACS. Results for men and women are thus presented together. When analysing the plasma protein inflammatory biomarkers, adjusted for differences in age and sex, we found that hsCRP $>2 \mathrm{mg} / \mathrm{L}$ at hospital admission was significantly associated with MI over UA (OR=1.75 (1.30 to 2.34)). MI was significantly associated with higher fibrinogen ( $p$ for trend=0.01), and also with SAA in the highest tertile $(\mathrm{OR}=1.66$ (1.16 to 2.36), but not in the trend test ( $\mathrm{p}$ for trend $=0.216$ ) (table 3$)$.

To separate an inflammatory response to myocardial tissue necrosis in patients with MI from that from a possible pre-existing inflammation, we analysed hsCRP

Table 1 Clinical characteristics of the study population

\begin{tabular}{|c|c|c|c|c|c|c|}
\hline \multirow[b]{2}{*}{ Risk factors } & \multicolumn{2}{|c|}{$\begin{array}{l}\text { Total } \\
n=908\end{array}$} & \multicolumn{2}{|c|}{$\begin{array}{l}\text { Men } \\
n=644\end{array}$} & \multicolumn{2}{|c|}{$\begin{array}{l}\text { Women } \\
n=264\end{array}$} \\
\hline & $\overline{\mathbf{m}}$ & (SD) & $\overline{\mathbf{m}}$ & (SD) & $\overline{\mathbf{m}}$ & (SD) \\
\hline Age (years) & 63.7 & 8.5 & 63.0 & $(8.6)$ & 65.5 & $(8.0)$ \\
\hline Serum cholesterol (mmol/L) & 6.2 & 1.3 & 6.0 & (1.3) & 6.6 & $(1.4)$ \\
\hline Plasma glucose $(\mathrm{mmol} / \mathrm{L})$ & 6.9 & 3.5 & 6.8 & (3.4) & 7.3 & (3.8) \\
\hline $\mathrm{HbA} 1 \mathrm{c}(\%)$ & 5.3 & 1.4 & 5.2 & (1.3) & 5.4 & $(1.7)$ \\
\hline hsCRP (mmol/L) & 9.2 & 21.8 & 9.3 & (21.9) & 9.0 & $(21.4)$ \\
\hline \multirow[t]{2}{*}{ Duration (min) } & 307 & 420 & 287 & $(418)$ & 360 & $(421)$ \\
\hline & $\mathbf{n}$ & $(\%)$ & $\mathbf{n}$ & (\%) & $\mathbf{n}$ & $(\%)$ \\
\hline Hypertension & 240 & $(27.5)$ & 169 & $(27.2)$ & 71 & $(28.1)$ \\
\hline Diabetes & 142 & (16.2) & 92 & (14.8) & 50 & (19.7) \\
\hline Smoking (current) & 191 & (22.1) & 148 & (24.1) & 43 & (17.1) \\
\hline Duration $\geq 240 \mathrm{~min}$ & 227 & (33.2) & 153 & (31.1) & 74 & (38.5) \\
\hline hsCRP >2 mg/L & 482 & $(60.5)$ & 341 & (59.3) & 141 & (63.5) \\
\hline
\end{tabular}


Table 2 Characteristics of plasma protein inflammatory biomarkers categorised by tertiles in men and women

\begin{tabular}{|c|c|c|c|}
\hline Risk factors & Range & $\begin{array}{l}\text { Men } \\
n=644 \\
n(\%)\end{array}$ & $\begin{array}{l}\text { Women } \\
n=264 \\
n(\%)\end{array}$ \\
\hline \multicolumn{4}{|c|}{ Serum amyloid (mg/L) } \\
\hline Tert 1 & $0.111-3.25$ & 209 (36.3) & $57(25.7)$ \\
\hline Tert 2 & $3.26-7.44$ & $191(33.2)$ & 75 (33.8) \\
\hline Tert 3 & $7.45-1570$ & $175(30.4)$ & $90(40.5)$ \\
\hline \multicolumn{4}{|l|}{ Fibrino (g/L) } \\
\hline Tert 1 & $1.5-3.3$ & $233(40.5)$ & 77 (33.8) \\
\hline Tert 2 & $3.4-4.0$ & $159(27.7)$ & 73 (32.0) \\
\hline Tert 3 & $4.1-10.0$ & $183(31.8)$ & $78(34.2)$ \\
\hline \multicolumn{4}{|l|}{ Leuco $\left(10^{9} / \mathrm{L}\right)$} \\
\hline Tert 1 & 2.49-7.39 & 196 (32.6) & $85(35.4)$ \\
\hline Tert 2 & $7.4-9.8$ & 198 (32.9) & $84(35.0)$ \\
\hline Tert 3 & $9.82-80.9$ & 207 (34.4) & 71 (29.6) \\
\hline \multicolumn{4}{|l|}{ Neutro $\left(10^{9} / \mathrm{L}\right)$} \\
\hline Tert 1 & $0.14-4.79$ & 191 (32.3) & $84(36.5)$ \\
\hline Tert 2 & $4.81-7.04$ & $196(33.1)$ & 78 (33.9) \\
\hline Tert 3 & $7.05-20.06$ & $205(34.6)$ & $68(29.6)$ \\
\hline \multicolumn{4}{|l|}{ Eosino $\left(10^{9} / \mathrm{L}\right)$} \\
\hline Tert 1 & $0-0.06$ & $155(27.2)$ & $84(36.8)$ \\
\hline Tert 2 & $0.07-0.14$ & $186(32.6)$ & 77 (33.8) \\
\hline Tert 3 & $0.15-9.12$ & 229 (40.2) & 67 (29.4) \\
\hline \multicolumn{4}{|l|}{ Baso $\left(10^{9} / \mathrm{L}\right)$} \\
\hline Tert 1 & $0-0.039$ & $229(40.7)$ & $95(43.0)$ \\
\hline Tert 2 & $0.04-0.059$ & $174(30.9)$ & $60(27.1)$ \\
\hline Tert 3 & $0.06-0.33$ & $160(28.4)$ & $66(29.9)$ \\
\hline \multicolumn{4}{|c|}{ Lympho $\left(10^{9} / \mathrm{L}\right)$} \\
\hline Tert 1 & $0.16-1.32$ & $206(34.8)$ & $71(30.9)$ \\
\hline Tert 2 & $1.33-1.88$ & $191(32.3)$ & $80(34.8)$ \\
\hline Tert 3 & $1.89-75.33$ & 195 (32.9) & 79 (34.3) \\
\hline \multicolumn{4}{|l|}{ Mono $\left(10^{9} / \mathrm{L}\right)$} \\
\hline Tert 1 & $0.04-0.4$ & 167 (28.4) & $116(50.7)$ \\
\hline Tert 2 & $0.41-0.56$ & $212(36.0)$ & $59(25.8)$ \\
\hline Tert 3 & $0.57-1.60$ & $210(35.7)$ & $54(23.6)$ \\
\hline \multicolumn{4}{|l|}{ T-cyt $\left(10^{9} / \mathrm{L}\right)$} \\
\hline Tert 1 & 85-198 & $228(38.1)$ & $54(23.6)$ \\
\hline Tert 2 & $199-247$ & $182(30.4)$ & 94 (39.3) \\
\hline Tert 3 & $248-680$ & $188(31.4)$ & $91(38.1)$ \\
\hline \multicolumn{4}{|l|}{ T-mcv (fL) } \\
\hline Tert 1 & $6.5-8.8$ & $221(39.4)$ & $69(31.4)$ \\
\hline Tert 2 & $8.9-9.4$ & $167(29.8)$ & $78(35.5)$ \\
\hline Tert 3 & $9.5-46.0$ & $173(30.8)$ & $73(33.2)$ \\
\hline
\end{tabular}

Missing data Serum amyloid ( $n=111)$, fibrinogen $(n=106)$, leucocytes $(n=67)$, neutrophils $(n=68)$, eosinophils $(n=110)$, basophils $(n=124)$, lymphocytes $(n=86)$, monocytes $(n=90)$, thrombocyte cell count $(n=71), T-m c v(N=127)$.

Baso, basophil cell count; eosino, eosinophil cell count; fibrino, fibrinogen; leuco, leucocyte cell count; lympho, lymphocyte cell count; mono, monocyte cell count; neutro, neutrophil cell count; T-cyt, thrombocyte cell count; T-mcv, thrombocyte median cell volume; tert, tertile.

levels in relation to duration from onset of chest pain until blood sampling. Controlling for differences in age and sex, we found a significant correlation of hsCRP with duration only in those patients with MI who had $\geq 240$ min duration since onset of symptoms ( $r=0.19$, $\mathrm{p}=0.033$ ) but not in patients with MI with a shorter
Table 3 Risk factors for an $\mathrm{Ml}$ as outcome of ACS (adjusted for differences in age and sex)

\begin{tabular}{|c|c|c|c|}
\hline Risk factors & OR & $95 \% \mathrm{Cl}$ & p Value \\
\hline Male sex & 1.59 & 1.19 to 2.13 & 0.002 \\
\hline Age (years) & 1.01 & 1.00 to 1.02 & 0.178 \\
\hline hsCRP >2 mg/L & 1.75 & 1.30 to 2.34 & $p$ for trend 0.037 \\
\hline $\begin{array}{l}\text { Sex (male vs } \\
\text { female) }\end{array}$ & 1.73 & 1.26 to 2.34 & $<0.001$ \\
\hline Age (years) & 1.00 & 0.98 to 1.02 & 0.872 \\
\hline \multicolumn{4}{|l|}{ Serum amyloid } \\
\hline Tert 1 & 1.0 & & $p$ for trend 0.216 \\
\hline Tert 2 & 1.39 & 0.98 to 1.97 & 0.063 \\
\hline Tert 3 & 1.66 & 1.16 to 2.36 & 0.006 \\
\hline \multicolumn{4}{|l|}{ Fibrino } \\
\hline Tert 1 & 1.00 & & $p$ for trend 0.010 \\
\hline Tert 2 & 1.26 & 0.90 to 1.94 & 0.174 \\
\hline Tert 3 & 1.62 & 1.12 to 2.35 & 0.011 \\
\hline \multicolumn{4}{|l|}{ Leuco } \\
\hline Tert 1 & 1.00 & & $p$ for trend $<0.001$ \\
\hline Tert 2 & 2.78 & 1.97 to 3.92 & $<0.001$ \\
\hline Tert 3 & 9.64 & 6.42 to 14.5 & $<0.001$ \\
\hline \multicolumn{4}{|l|}{ Neutro } \\
\hline Tert 1 & 1.00 & & $p$ for trend $<0.001$ \\
\hline Tert 2 & 2.96 & 2.09 to 4.20 & $<0.001$ \\
\hline Tert 3 & 8.91 & 5.97 to 13.3 & $<0.001$ \\
\hline \multicolumn{4}{|l|}{ Eosino } \\
\hline Tert 1 & 1.00 & & $p$ for trend 0.002 \\
\hline Tert 2 & 0.65 & 0.45 to 0.94 & 0.021 \\
\hline Tert 3 & 0.56 & 0.39 to 0.80 & 0.001 \\
\hline \multicolumn{4}{|l|}{ Mono } \\
\hline Tert 1 & 1.00 & & $p$ for trend $<0.001$ \\
\hline Tert 2 & 1.29 & 0.92 to 1.82 & 0.140 \\
\hline Tert 3 & 3.18 & 2.20 to 4.61 & $<0.001$ \\
\hline \multicolumn{4}{|c|}{ 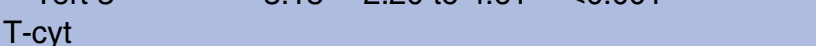 } \\
\hline Tert 1 & 1.00 & & $p$ for trend 0.016 \\
\hline Tert 2 & 1.14 & 0.81 to 1.61 & 0.445 \\
\hline Tert 3 & 1.48 & 1.05 to 2.09 & 0.025 \\
\hline \multicolumn{4}{|l|}{ T-mcv } \\
\hline Tert 1 & 1.00 & & $p$ for trend $<0.001$ \\
\hline Tert 2 & 0.46 & 0.32 to 0.65 & $<0.001$ \\
\hline Tert 3 & 0.51 & 0.35 to 0.72 & $<0.001$ \\
\hline
\end{tabular}

Associations between risk factors and an adverse outcome of ACS were estimated using binary logistic regression and expressed as ORs with $95 \% \mathrm{Cls}$ adjusting for differences in age and sex. Plasma levels of hsCRP were dichotomised at $2 \mathrm{mg} / \mathrm{L}$, while other biomarkers were divided in tertiles for categorical comparisons using tertile 1 as reference. The continuous format of the variables was used to test for trend, however, due to skewed distributions, the tertiles were used as a linear variable for trend test of concentration of fibrinogen, eosinophil cell count and T-mov.

ACS, acute coronary syndrome; eosino, eosinophil cell count; fibrino, fibrinogen; hsCRP, high-sensitivity $\mathrm{C}$ reactive protein; leuco, leucocyte cell count; MI, myocardial infarction; mono, monocyte cell count; neutro, neutrophil cell count; T-cyt, thrombocyte cell count; T-mcv, thrombocyte median cell volume; tert, tertile.

duration $(\mathrm{r}=0.02, \mathrm{p}=0.777)$, or in patients with UA with $\geq 240 \mathrm{~min}$ duration or shorter duration $(\mathrm{r}=-0.10$, $\mathrm{p}=0.452$ and $\mathrm{r}=-0.02, \mathrm{p}=0.779$, respectively). After including smoking and time duration since onset of 
Table 4 Risk factors for an $\mathrm{Ml}$ as outcome of ACS

\begin{tabular}{|c|c|c|c|}
\hline Risk factors & OR & $95 \% \mathrm{Cl}$ & p Value \\
\hline \multicolumn{4}{|c|}{$\begin{array}{l}\text { Covariates in model: sex, age, smoking, duration of } \\
\text { symptoms }\end{array}$} \\
\hline & & & $p$ for trend 0.225 \\
\hline hsCRP >2 mg/L & 1.40 & 1.00 to 1.96 & 0.049 \\
\hline Male sex & 1.50 & 1.04 to 2.17 & 0.031 \\
\hline Age (years) & 1.01 & 0.99 to 1.03 & 0.566 \\
\hline $\begin{array}{l}\text { Smoking } \\
\text { (yes/no) }\end{array}$ & 2.15 & 1.39 to 3.32 & 0.001 \\
\hline $\begin{array}{l}\text { Duration } \\
(\geq 4 \text { vs }<4 \mathrm{~h})\end{array}$ & 1.41 & 0.98 to 2.03 & 0.061 \\
\hline \multicolumn{4}{|l|}{ Serum amyloid } \\
\hline Tert 1 & 1.0 & & $p$ for trend 0.679 \\
\hline Tert 2 & 1.43 & 0.96 to 2.13 & 0.078 \\
\hline Tert 3 & 1.28 & 0.84 to 1.93 & 0.248 \\
\hline \multicolumn{4}{|l|}{ Fibrino } \\
\hline Tert 1 & 1.00 & & $p$ for trend 0.031 \\
\hline Tert 2 & 1.19 & 0.82 to 1.74 & 0.349 \\
\hline Tert 3 & 1.62 & 1.03 to 2.55 & 0.039 \\
\hline \multicolumn{4}{|l|}{ Leuco } \\
\hline Tert 1 & 1.00 & & $p$ for trend $<0.001$ \\
\hline Tert 2 & 2.58 & 1.74 to 3.83 & $<0.001$ \\
\hline Tert 3 & 7.39 & 4.69 to 11.6 & $<0.001$ \\
\hline \multicolumn{4}{|l|}{ Neutro } \\
\hline Tert 1 & 1.00 & & $p$ for trend $<0.001$ \\
\hline Tert 2 & 2.58 & 1.74 to 3.83 & $<0.001$ \\
\hline Tert 3 & 7.39 & 4.69 to 11.6 & $<0.001$ \\
\hline \multicolumn{4}{|l|}{ Eosino } \\
\hline Tert 1 & 1.00 & & $p$ for trend 0.003 \\
\hline Tert 2 & 0.69 & 0.45 to 1.07 & 0.069 \\
\hline Tert 3 & 0.54 & 0.35 to 0.81 & 0.003 \\
\hline \multicolumn{4}{|l|}{ Mono } \\
\hline Tert 1 & 1.00 & & $p$ for trend $<0.001$ \\
\hline Tert 2 & 0.99 & 0.67 to 1.47 & 0.978 \\
\hline Tert 3 & 2.36 & 1.54 to 3.62 & $<0.001$ \\
\hline \multicolumn{4}{|l|}{ T-cyt } \\
\hline Tert 1 & 1.00 & & $p$ for trend 0.052 \\
\hline Tert 2 & 1.12 & 0.75 to 1.66 & 0.584 \\
\hline Tert 3 & 1.61 & 1.08 to 2.39 & 0.020 \\
\hline \multicolumn{4}{|l|}{ T-mcv } \\
\hline Tert 1 & 1.00 & & $p$ for trend $<0.001$ \\
\hline Tert 2 & 0.41 & 0.27 to 0.61 & $<0.001$ \\
\hline Tert 3 & 0.45 & 0.30 to 0.68 & $<0.001$ \\
\hline
\end{tabular}

Multivariate analysis adjusted for differences in age, sex, smoking and duration of symptoms.

Associations between risk factors and an adverse outcome of ACS were estimated using binary logistic regression and expressed as ORs with $95 \%$ Cls. All models included sex, age, smoking and duration of chest pain as covariates beside the specified risk factor itself. Plasma levels of hsCRP $\geq 2 \mathrm{mg} / \mathrm{L}$ were compared to those below, while other biomarkers were divided in tertiles for categorical comparisons using tertile 1 as reference. The continuous format of the variables was used to test for trend, however, due to skewed distributions, the tertiles were used as a linear variable for trend test of concentration of fibrinogen, eosinophil cell count and T-mcv.

ACS, acute coronary syndrome; eosino, eosinophil cell count; fibrino, fibrinogen; hsCRP, high-sensitivity $\mathrm{C}$ reactive protein; leuco, leucocyte cell count; MI, myocardial infarction; mono, monocyte cell count; neutro, neutrophil cell count; T-cyt, thrombocyte cell count; T-mcv, thrombocyte median cell volume; tert, tertile. chest pain in the model, hsCRP $>2 \mathrm{mg} / \mathrm{L} \quad(\mathrm{OR}=1.40$ (1.00 to 1.96)) and fibrinogen ( $\mathrm{p}$ for trend $=0.031$ ) remain associated with MI over UA (table 4 ). Time duration since onset of symptoms, as such, did not reach a statistically significant association with MI over UA (OR 1.41 (0.98 to 2.03$)$, table 4$)$.

The strongest associations with MI over UA were found when haematological variables (blood cells) were analysed (tables 3 and 4). Of circulating inflammatory blood cells, higher counts of neutrophils and monocytes, and lower counts of eosinophils, were associated with a worse outcome of ACS (table 3). These associations were not affected when adjusting for smoking and duration of symptoms (table 4) or in trend tests where the associations were highly significant $(p=0.003)$. In the multivariate models, the outcome for smoking (highly significant) and duration of symptoms (borderline significant) were generally the same with all inflammatory biomarkers, and is thus shown only in the first model with hsCRP. In contrast, lymphocyte and basophil counts showed no association with outcome (data not shown). Also, we found that higher thrombocyte count was associated with MI (tables 3 and 4). Interestingly, a smaller thrombocyte mean volume was significantly associated with MI when compared to UA ( $p$ for trend $<0.001$ ).

\section{DISCUSSION}

\section{Principal findings}

In the current study, we showed that levels of inflammatory biomarkers at the time of admission are associated with a more severe outcome in the case of ACS (ie, predisposition towards MI, rather than UA). We found significant differences in blood cell profiles between an MI or UA outcome, with elevated neutrophils, monocytes and platelet counts in MI, together with a reduced eosinophil count and lower mean platelet volume (MPV). Plasma biomarkers for inflammation (hsCRP, fibrinogen and SAA) showed weaker associations. Our results indicate that a pre-existing inflammation predisposes to a more severe outcome in ACS. ${ }^{8}$

\section{Plasma biomarkers of inflammation and the outcome of ACS}

Previously, we used the CHAPS material to show that genetic variations of thrombotic factors are associated with ACS outcome ${ }^{9}$ and, furthermore, that acquired risk factors, smoking and impaired glucose homoeostasis together with male sex, predispose to $\mathrm{MI}$ over $\mathrm{UA} .{ }^{6} \mathrm{We}$ have here shown that a more pronounced state of inflammation conferred an increased risk towards MI, rather than UA, in ACS. It is well established that a lowgrade inflammation has a pathogenic role for the progression of atherosclerotic coronary artery lesions, ${ }^{1}$ however, less known is to what extent a pre-existing inflammation can influence the outcome of ACS. ${ }^{2}$ It could be argued that elevation of inflammatory biomarkers in patients with ACS may reflect myocardial injury 
rather than underlying inflammation. However, fibrinogen, CRP and SAA are induced by cytokine signalling for example, by interleukin (IL) 1, tumour necrosis factor and IL- $6^{1}{ }^{10}{ }^{11}$-and, due to a period of de novo synthesis and secretion of these proteins, there is a time lag before a rise in plasma concentration becomes detectable during the acute phase of inflammation. The average lag time of this response is $8 \mathrm{~h}^{10}$ and, furthermore, in patients with MI, there is a known latency of 6$12 \mathrm{~h}$ from onset of chest pain to a rise in CRP plasma concentrations. ${ }^{12}$ In line with this, we observed a correlation between hsCRP and time only in patients with MI where the duration between symptom onset and blood sampling exceeded $4 \mathrm{~h}$, indicating that the inflammatory response to myocardial injury had a lag time of several hours. Thus, the associations with MI over UA that we observe in patients with duration of chest pain of $<4 \mathrm{~h}$ indicate that in ACS a higher pre-existing inflammation predisposes to a more severe outcome. In CHAPS, we previously found current smoking to be strongly associated with MI, but not UA. ${ }^{6}$ We considered the possibility that these results could be explained by the known inflammatory effect of smoking. ${ }^{13-15}$ However, the significant associations between MI and hsCRP and fibrinogen, were still observed when adjusting for smoking.

\section{Circulating inflammatory blood cells and the outcome of ACS}

The strongest associations with MI over UA were observed when analysing circulating inflammatory blood cells-independent of smoking and time duration of symptoms to blood sampling. In contrast to plasma protein biomarkers that require synthesis before there is a detectable increase in levels, preformed blood cells can be quickly mobilised into circulation by demargination from the vessel wall and egress from the bone marrow. ${ }^{16}$ Pro-inflammatory cytokines stimulate neutrophil and monocyte production in the bone marrow. Stress-induced release of endogenous catecholamine and glucocorticoids can mobilise these stores shortly after the onset of chest pain. Thus, the magnitude of rise in cell count can reflect the size of the preformed cell pool that has been increased by a pre-existing lowgrade inflammation. ${ }^{16}$ Thus, the difference we observed in neutrophil and monocyte count, between MI and UA, indicated a pre-existing inflammation preceding the ACS, consistent with our observations regarding hsCRP and fibrinogen levels. In a recent population-based cohort study, Adamsson Eryd et $\mathrm{al}^{17}$ found an association between increased neutrophil count, and incidence of coronary events and increased case fatality rate during follow-up, in line with a previous meta-analysis of several prospective population studies. ${ }^{18}$ A possible explanation for our observation-that neutrophilia was associated with MI when compared to UA-is a hypercoagulable or thrombo-resistant state, as previously indicated by reduced efficiency of thrombolytic therapy or primary percutaneus coronary interventions in patients with MI with elevated white cell count. ${ }^{19-21}$ In this context, it is interesting that a reduced efficiency of primary PCIs in patients with MI has recently been found to be associated with an increased amount of neutrophil extracellular traps (NETs) in aspirated coronary thrombi, ${ }^{22}$ adding support to the possibility of an important role for neutrophils in the ACS thrombotic process. An association of an increased monocyte count and coronary events has previously been reported from population studies. ${ }^{23}{ }^{24}$ A possible mechanism relates to the heavy infiltration of monocytes/macrophages that is characteristic of a thin fibrous cap on a vulnerable plaque. ${ }^{25}$ Thus, a pre-existing monocytosis in MI, compared to UA, might lead to greater monocytoid infiltration, and predispose to a more extensive thrombotic process following plaque rupture. ${ }^{25}$ Interestingly, we found significantly lower eosinophil counts in patients with MI, compared to those with UA, consistent with recent reports. ${ }^{26}$ Eosinophils have been detected in aspirates from thrombi in patients with MI, ${ }^{26}{ }^{27}$ suggesting a possible role for this cell type in the progression of the thrombotic process in ACS. Our observation could indicate an active consumption of eosinophils in MI, or reflect a pre-existing condition of elevated eosinophil count and hypersensitivity inflammation that could predispose to UA. Indeed, Erdogan $e t a l^{28}$ reported a significantly higher eosinophil count in patients with UA, but not in patients with MI, when compared to controls. Thrombocytes are key effector cells in an inflammatory process $^{29} 30$ and an increase of the thrombocyte count is part of an inflammatory state. ${ }^{31}$ Recently, the role of thrombocytes in vascular inflammation and the thrombotic process in coronary artery disease (CAD) has been highlighted, ${ }^{5} 3233$ with an increased MPV reported to be associated with acute cardiovascular events. ${ }^{34}{ }^{35}$ In a systematic review and meta-analysis using pooled results from 16 cross-sectional studies involving 2809 patients, MPV was found to be significantly higher in patients with ACS than in patients with stable CAD or in healthy individuals. $^{34}$ No significant difference in MPV was found between patients with MI and those with UA. Individual studies have shown both higher and lower MPV in patients with MI over those with UA. ${ }^{36} 37$ In $\mathrm{ACS}$, thrombocytes are involved in a dynamic thrombotic process, with consumption of preferentially more reactive large-sized thrombocytes. ${ }^{35}$ This is extensive and permanent in MI, in contrast to the recurrent episodes of (temporary) coronary platelet aggregation and consumption in UA, ${ }^{38} 39$ tending to result in a lower MPV in MI than in UA, as in our study and the study of Mathur et al. ${ }^{37}$ This is, however, in most studies, probably counterbalanced by the effects on thrombocytes of a more intense pre-existing inflammation in MI, leading to a similar MPV in MI and UA. ${ }^{34}$

\section{Strengths and limitations}

The strength and novelty of CHAPS is due to the unique nature of the patient cohort. The patients were recruited 
before the introduction of PCI, CABG and modern antithrombotic drugs, in the standard management of ACS. These interventions would otherwise influence the thrombotic processes involved in ACS. The absence of them at that time made it possible for us to identify progression to either MI or UA as distinct outcome groups within the cohort. Furthermore, the study was based in one centre with the same two cardiologists assessing and categorising all patients, using consistent criteria. There are limitations of the study that should be acknowledged. Smoking was defined as current smoker or nonsmoker, and thus ex-smokers (cessation $>1$ month ago) were classified into the non-smoker group, however, previous studies indicate that the increased risk for cardiovascular events associated with smoking decreases rapidly after smoking cessation. ${ }^{40}$ Furthermore, duration was based on time of onset as reported by patients at admission, which may confer a misclassification in some cases. Biochemical analyses of fibrinogen and blood cells were performed over a period of 4 years. The hospital laboratory used standardised and certified methods, providing consistency over time. Analyses of hsCRP and SAA were performed using frozen samples stored at $-80^{\circ} \mathrm{C}$ for 15 years; quality assurance work at the laboratory has shown that storage of samples at $-80^{\circ}$ $\mathrm{C}$ did not influence determined hsCRP and SAA levels. Furthermore, not all patients have complete data for laboratory analyses. In the different multivariate analyses performed, participants with missing data for any included marker were automatically excluded, leaving about $70 \%$ of patients in the regression for the full model. Still, outcomes are strong and consistent with the age and sex adjusted model, leaving $90 \%$ of patients in the regression. Furthermore, the overall patterns show a high internal consistency. As refined criteria and more sensitive and specific biomarkers are implemented, the definition of MI continues to evolve. It is likely that some of the UA cases in our study would now been diagnosed as NSTEMI, using recent criteria required for MI diagnosis. ${ }^{8}$ Also, as CHAPS is a single centre study, and treatments and risk factor profiles have partly developed since the study was performed, the results would therefore not necessarily be generalised to a broader modern population.

\section{Conclusions and possible clinical implications}

In conclusion, while inflammation is well established as a major risk factor for development of CAD and risk of future events, our study indicates the further role of inflammation in a more severe outcome in the case of ACS. Our data suggest that neutrophil levels can have a prognostic value in patients with ACS, as previously proposed. ${ }^{17}$ The observed differences in ACS outcome associated with inflammation and blood cell profiles raise several hypotheses that warrant further investigation. It is possible that UA and MI represent different entities of ACS that involve different pathological mechanisms. Establishing such mechanisms at the cellular level could lead to optimisation of pharmacological treatment for CAD and ACS.

\section{Author affiliations}

${ }^{1}$ Department of Proteomics, KTH, Science for Life Laboratory Stockholm, Solna, Sweden

${ }^{2}$ Centre for Hematology, Karolinska University Hospital, Stockholm, Sweden

${ }^{3}$ Department of Clinical Sciences in Malmö, Lund University, Malmö, Sweden

${ }^{4}$ Blekinge Centre of Competence, Karlskrona, Sweden

${ }^{5}$ Department of Laboratory Medicine, Blekinge County Hospital, Karlskrona, Sweden

${ }^{6}$ Research Unit of General Practice, University of Southern Denmark, Odense, Denmark

${ }^{7}$ Department of Clinical Sciences in Malmö, Lund University, Malmö, Sweden ${ }^{8}$ Department of Community Medicine/Primary Health Care, University of Gothenburg, Göteborg, Sweden

Acknowledgements The authors wish to thank Dr Lynn Butler for valuable suggestions and comments on the manuscript. Furthermore, they want to thank senior cardiology consultant Dr Per-Ola Bengtsson, for evaluating and categorising the patients included in the study.

Contributors HO, LR and MF designed and initiated the original CHAPS cohort on which the current study is based. MF conducted the patient inclusion, reviewed all cases, collected patient information and compiled the data files. JO, HF, IV, HO, AH, LR and UL conceived and designed the current study. IV and MP collected and compiled the laboratory data. HF and UL performed the statistical analyses, and compiled the results. JO, MF, HF, IV, $\mathrm{HO}, \mathrm{AH}, \mathrm{LR}$ and $\mathrm{UL}$ interpreted the results. JO, $\mathrm{HO}$ and $\mathrm{UL}$ drafted the paper. MF, HF, IV and LR contributed to critical revision for important intellectual content. All the authors approved the final manuscript. JO is the guarantor.

Funding J0 was funded by a grant from Stockholm County Council (SLL) and from Royal Institute of Technology (KTH). The Carlscrona Heart Attack Prognosis Study (CHAPS) has been supported by Blekinge County Council.

Competing interests None declared.

Patient consent Obtained.

Ethics approval Regional Carlscrona Heart Attack Prognosis Study (CHAPS) was approved by the Regional Ethical Review Board, Lund, Sweden (EPN 2009/762 and LU 298-91).

Provenance and peer review Not commissioned; externally peer reviewed.

Data sharing statement No additional data are available.

Open Access This is an Open Access article distributed in accordance with the Creative Commons Attribution Non Commercial (CC BY-NC 4.0) license, which permits others to distribute, remix, adapt, build upon this work noncommercially, and license their derivative works on different terms, provided the original work is properly cited and the use is non-commercial. See: http:// creativecommons.org/licenses/by-nc/4.0/

\section{REFERENCES}

1. Packard RR, Libby P. Inflammation in atherosclerosis: from vascular biology to biomarker discovery and risk prediction. Clin Chem 2008;54:24-38.

2. Libby P. Mechanisms of acute coronary syndromes and their implications for therapy. N Engl J Med 2013;368:2004-13.

3. Crea F, Liuzzo G. Pathogenesis of acute coronary syndromes. J Am Coll Cardiol 2013;61:1-11.

4. Buffon A, Biasucci LM, Liuzzo G, et al. Widespread coronary inflammation in unstable angina. N Engl J Med 2002;347:5-12.

5. Croce K, Libby P. Intertwining of thrombosis and inflammation in atherosclerosis. Curr Opin Hematol 2007;14:55-61.

6. Odeberg J, Freitag M, Forssell $\mathrm{H}$, et al. The influence of smoking and impaired glucose homoeostasis on the outcome in patients presenting with an acute coronary syndrome: a cross-sectional study. BMJ Open 2014;4:e005077.

7. Ridker PM, Group JS. Rosuvastatin in the primary prevention of cardiovascular disease among patients with low levels of low-density lipoprotein cholesterol and elevated high-sensitivity C-reactive 
protein: rationale and design of the JUPITER trial. Circulation 2003;108:2292-7.

8. Thygesen K, Alpert JS, Jaffe AS, et al. Third universal definition of myocardial infarction. Eur Heart J 2012;33:2551-67.

9. Odeberg J, Freitag M, Odeberg H, et al. Severity of acute coronary syndrome is predicted by interactions between fibrinogen concentrations and polymorphisms in the GPIIla and FXIII genes. J Thromb Haemost 2006;4:909-12.

10. Manley PN, Ancsin JB, Kisilevsky R. Rapid recycling of cholesterol: the joint biologic role of $\mathrm{C}$-reactive protein and serum amyloid $\mathrm{A}$. Med Hypotheses 2006;66:784-92.

11. Kisilevsky R, Manley PN. Acute-phase serum amyloid A: perspectives on its physiological and pathological roles. Amyloid 2012;19:5-14.

12. Théroux $P$. The past, the present, the future. In: Théroux $P$, ed. Acute coronary syndromes: a companion to Braunwald's Heart Disease. 2nd edn. Philadelphia, PA: Saunders, 2011:1-13.

13. Benowitz NL. Cigarette smoking and cardiovascular disease: pathophysiology and implications for treatment. Prog Cardiovasc Dis 2003;46:91-111.

14. Ambrose JA, Barua RS. The pathophysiology of cigarette smoking and cardiovascular disease: an update. J Am Coll Cardiol 2004;43:1731-7.

15. Salahuddin S, Prabhakaran D, Roy A. Pathophysiological mechanisms of tobacco-related CVD. Glob Heart 2012;7:113-20.

16. Rice L, Jung M. Neutrophilic leukocytosis, neutropenia monocytosis, and monocytopenia. In: Hoffman R, Benz E, Silberstein L, et al, eds. Hematology. 6th edn. Philadelpia, PA: Sanders, 2014:640-6.

17. Adamsson Eryd S, Smith JG, Melander O, et al. Incidence of coronary events and case fatality rate in relation to blood lymphocyte and neutrophil counts. Arterioscler Thromb Vasc Biol 2012;32:533-9.

18. Wheeler JG, Mussolino ME, Gillum RF, et al. Associations between differential leucocyte count and incident coronary heart disease: 1764 incident cases from seven prospective studies of 30,374 individuals. Eur Heart J 2004;25:1287-92.

19. Barron HV, Cannon CP, Murphy SA, et al. Association between white blood cell count, epicardial blood flow, myocardial perfusion, and clinical outcomes in the setting of acute myocardial infarction: a thrombolysis in myocardial infarction 10 substudy. Circulation 2000;102:2329-34.

20. Varasteh-Ravan HR, Ali-Hassan-Sayegh S, Shokraneh S, et al. Relationship of admission mean platelet volume, platelet distribution width and white blood cells with ST resolution in patients with acute ST segment elevation myocardial infarction treated with streptokinase without history of previous cardiovascular surgery. Perspect Clin Res 2013;4:125-9.

21. Maden O, Kacmaz F, Selcuk H, et al. Relationship of admission hematological indexes with myocardial reperfusion abnormalities in acute ST segment elevation myocardial infarction patients treated with primary percutaneous coronary interventions. Can J Cardiol 2009;25:e164-8.

22. Mangold A, Alias S, Scherz T, et al. Coronary neutrophil extracellular trap burden and deoxyribonuclease activity in ST-elevation acute coronary syndrome are predictors of ST-segment resolution and infarct size. Circ Res 2015;116:1182-92.

23. Lee CD, Folsom AR, Nieto FJ, et al. White blood cell count and incidence of coronary heart disease and ischemic stroke and mortality from cardiovascular disease in African-American and white men and women: atherosclerosis risk in communities study. $A m \mathrm{~J}$ Epidemiol 2001;154:758-64.

24. Olivares R, Ducimetiere P, Claude JR. Monocyte count: a risk factor for coronary heart disease? Am J Epidemiol 1993;137:49-53.

25. Falk E, Nakano M, Bentzon JF, et al. Update on acute coronary syndromes: the pathologists' view. Eur Heart J 2013;34:719-28.

26. Jiang P, Wang DZ, Ren YL, et al. Significance of eosinophil accumulation in the thrombus and decrease in peripheral blood in patients with acute coronary syndrome. Coron Artery Dis 2015;26:101-6.

27. Sakai T, Inoue S, Matsuyama TA, et al. Eosinophils may be involved in thrombus growth in acute coronary syndrome. Int Heart $J$ 2009;50:267-77.

28. Erdogan O, Gul C, Altun A, et al. Increased immunoglobulin E response in acute coronary syndromes. Angiology 2003;54:73-9.

29. Weyrich AS, Lindemann S, Zimmerman GA. The evolving role of platelets in inflammation. $J$ Thromb Haemost 2003;1:1897-905

30. Vieira-de-Abreu A, Campbell RA, Weyrich AS, et al. Platelets: versatile effector cells in hemostasis, inflammation, and the immune continuum. Semin Immunopathol 2012;34:5-30.

31. Kaushansky K. Reactive thrombocytosis. In: Kaushansky K, Lichtman AH, Seligsohn U, et al, eds. Williams hematology. 8th edn. New York, NY: McGraw-Hill, 2010:1929-32.

32. Libby $\mathrm{P}$, Lichtman $\mathrm{AH}$, Hansson GK. Immune effector mechanisms implicated in atherosclerosis: from mice to humans. Immunity 2013;38:1092-104.

33. Vieira-de-Abreu A, Rondina MT, Weyrich AS, et al. Inflammation. In: Michelson A, ed. Platelets. 3th edn. London, UK: Academic Press, 2013:733-66.

34. Chu SG, Becker RC, Berger PB, et al. Mean platelet volume as a predictor of cardiovascular risk: a systematic review and meta-analysis. J Thromb Haemost 2010;8:148-56.

35. Gasparyan AY, Ayvazyan L, Mikhailidis DP, et al. Mean platelet volume: a link between thrombosis and inflammation? Curr Pharm Des 2011;17:47-58.

36. Senaran $\mathrm{H}$, lleri M, Altinbas $\mathrm{A}$, et al. Thrombopoietin and mean platelet volume in coronary artery disease. Clin Cardiol 2001;24:405-8.

37. Mathur A, Robinson MS, Cotton J, et al. Platelet reactivity in acute coronary syndromes: evidence for differences in platelet behaviour between unstable angina and myocardial infarction. Thromb Haemost 2001;85:989-94.

38. Willerson JT, Golino P, Eidt J, et al. Specific platelet mediators and unstable coronary artery lesions. Experimental evidence and potential clinical implications. Circulation 1989;80:198-205.

39. Rentrop KP. Thrombi in acute coronary syndromes: revisited and revised. Circulation 2000;101:1619-26.

40. Mackay DF, Irfan MO, Haw S, et al. Meta-analysis of the effect of comprehensive smoke-free legislation on acute coronary events. Heart 2010;96:1525-30. 